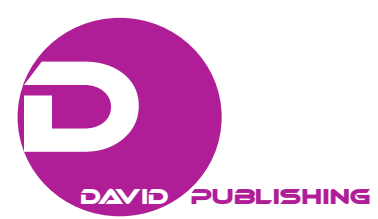

\title{
The Role of Knowledge Processing Management in SME Development and Economic Growth
}

\author{
Kambiz Talebi \\ University of Tehran, Tehran, Iran \\ Mahla Zare Mehrjerdi \\ Drexel University, Philadelphia, USA \\ Seyed Mohammad Reza Akbari \\ Islamic Azad University, Marvdasht, Iran
}

\begin{abstract}
Small and medium enterprises (SMEs) contribute to economic development by virtue of their employers' numbers and increasing share in Gross National Product (GNP). SMEs strengthen the resilience of the countries to face a competitive and challenging global environment. A large body of investigations has been done on the identification of factors which facilitate the creation or development of SMEs. One of the most important factors which affect the creation and development of SMEs is individuals' information processing. In this study, by using a theoretical model, authors tried to determine the role of knowledge processing in recognizing those opportunities which lead to SME creation and development. Based on Olson's theory (1985), authors considered two moods for cognitions styles which affect knowledge processing in entrepreneurs and lead to SME creation: intuition versus analysis and the result of factor analysis showed that opportunities are both born and created but not by accident, authors found those entrepreneurs who develop and create SMEs have special characteristics in recognizing and processing the information. They can process the business related information much faster than typical people. This ability allows them to turn their knowledge into a large endowment of assets which form a new SME or extend an existing one.
\end{abstract}

Keywords: economic growth, knowledge process, SME

\section{Knowledge Processing in SME Management}

SME development is the process of recognizing profitable opportunities and founding an organization to exploit them. Information resources are scare. Due to the asymmetry of information, individuals with higher alertness can grasp information and exploit it faster than others. Hence, one of the most important factors which contribute to SME development through opportunity recognition is the information processing style of an entrepreneur (Julien \& Vaghely, 2002). During last three decades, scholars showed that knowledge processing style is mainly affected by the individual's cognitive styles. While an individual has an intention to create a

Kambeiz Talebi, associate professor, entrepreneurship, University of Tehran, Tehran, Iran.

Mahla Zare Mehrjerdi, graduate economics student, Drexel University, Philadelphia, USA

Seyed Mohammad Reza Akbari, young researcher and elite club, Marvdasht Branch, Islamic Azad University, Marvdasht, Iran.

Correspondence concerning this article should be addressed to Mahla Zare Mehrjerdi, Gerri C. LeBow Hall 1001, Economics Department, Drexel University, Philadelphia, Pennsylvania, USA. 
venture, the cognitive styles may nurture some self-cognitions. Thus, this may lead to preventing or encouraging a person to follow his/her intention (Timmons \& Spinelli, 2004).

Inspite of enhance literature body on knowledge processing and SMEs, we know very little about the ways in which cognitive styles develop or inhibit the SME development through different information processing. Hence, the main objective of this study is to clarify the relation between SME development and knowledge processing style by considering the mediator role of different cognitive styles.

This study contributes to the SME development literature body in two main ways:

(1) First of all, this paper presents some theoretical facts for various kinds of knowledge and information processing methods and determines its relation with different cognitive style.

(2) Second, the paper tries to prove the exact amount of the effects of independent variables (information processing styles) on SME development.

\section{Theory and Hypothesis}

In order to build the paper's hypothesis, the authors refer to Gartner's (1985) conceptual framework on SME development.

\section{Gartner's Conceptual Framework of New Venture Creation}

Gartner (1985), in his well-known article, drew a question on SME development which is what are the main differences of each entrepreneur's venture with the others. He then stressed that for answering this question, one should integrate the constituents variables of various ventures.

He believed the creation of an entrepreneurial venture is a multidimensional phenomenon, entrepreneurs, and their SMEs, their activities and responses and the environment which they have to operate are, at the same time, complicated and unique. Thus, NVC (new venture creation) highly depends on the components of the comprehensive model which he defined as below (Figure 1):

Accordingly, the assumptions can be made as the following:

H1: Information processing effects business developing via cognitive scripts;

$\mathrm{H} 2$ : Information processing increases the probability of business opportunity recognition.

\section{Various Kinds of Knowledge From Hayek's View}

Hayek (1937) determined two main kinds of knowledge:

(1) The main body of knowledge which is scientific and sustainable and can be used through each field by those fields' experts;

(2) Diffused information about determined time and places which are important for individuals only because it helps them to judge about different situations.

The second type of knowledge is the key for economic development in societies (Hayek, 1937).

\section{Information Processing and SME's Development Through Entrepreneurial Opportunity Recognition}

How individuals' information processing can help them to identify entrepreneurial opportunities and venture creation is the question which this study tries to answer in this section. Information processing is the dynamic combination of heuristics and algorithmic information.

Entrepreneur as an information processor, uses both of information type for business's opportunity identification. Recent studies introduced individual's information processing as the most important ingredient in NVC (Vaghely \& Julien, 2010). 


\section{INDIVIDUAL(S)}

Cognitive, demographic, and sociological factors: locus of control, risk taking propensity, job satisfaction, previouswork experience, entrepreneurial parents age, and education

\section{ENVIRONMENT}

Venture capital availability

Presence of experienced entrepreneurs technically

Skilled labor force accessibility of suppliers

Accessibility of customers or new markets

Governmental influences

Proximity of universities

Availability of land or facilities

Accessibility of transportation

Attitude of the area population

Availability of supporting services

Living conditions

High occupational and industrial differentiation

High percentages of recent immigrants in the population

Large industrial base

Larger size urban areas

Availability of financial resources

Barriers to entry

Rivalry among existing competitors

Pressure from substitute products

Bargaining power of buyers

Bargaining power of suppliers

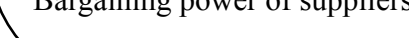

\section{PROCESS}

The entrepreneur locates a business opportunity

The entrepreneur accumulates resources

The entrepreneur markets products and services

The entrepreneur produces the product

The entrepreneur builds an organization

The entrepreneur responds to government and society

Figure 1. The variables of conceptual framework for venture creation (Gartner, 1985).

\section{Research Design}

\section{Research Framework}

On the basis of Gartner's model, this study will establish the theoretical framework by the logical deduction and group discussions as shown in Figure 2. The study's hypothesis has been shown in a theoretical 
process as below. Based on the paper's research design, individuals try to process explicit and tacit knowledge through their cognitive scripts. The way they process their information will then lead to whether start an establishment by recognizing business opportunities or not.

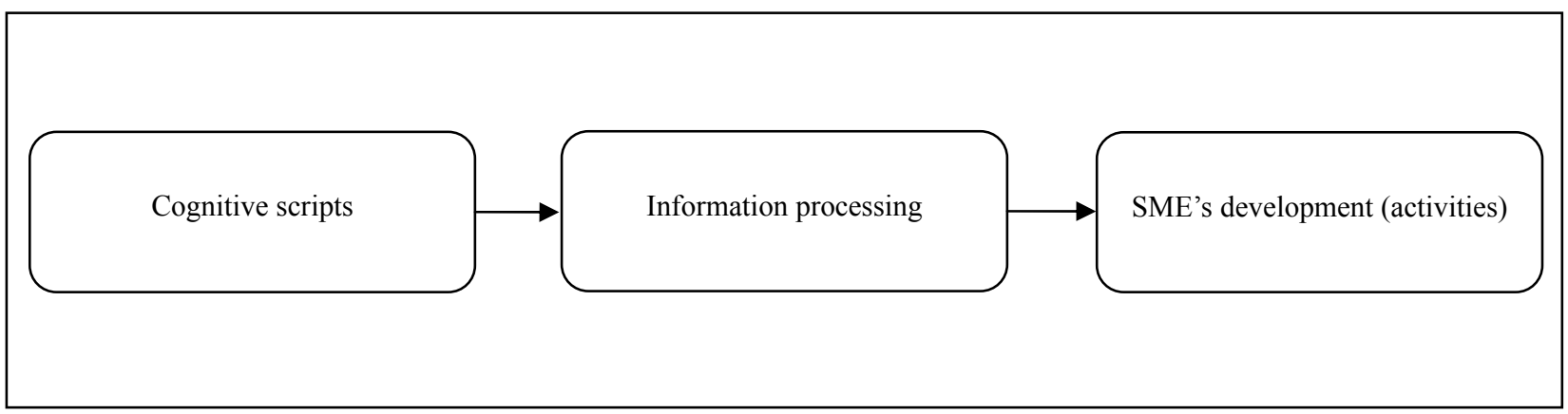

Figure 2. Structural path diagram of theory and hypothesis.

\section{Definition and Measurement of Variables}

To insure the validity and reliability of the questionnaire, this research consulted the mature scales in foreign references in the process of operational definition and measurement of the variables.

The preliminary questionnaire was examined carefully and critically by the specialists of the field, and revisions are made according to the feedbacks. The questionnaire adopts 10-point Likert scales $(1=$ extremely bad, $10=$ very good).

\section{Research Method}

\section{Research Subject}

The study assumes that information processing styles affect SME development activities through individual's cognitive scripts. For estimating this assumption, authors used multidimensional regression model.

Key variables in knowledge processing. (1) Intuition. Psychologist of cognitive school defines intuition as the immediate knowing of something without the conscious use of reasoning. Knowing is different from reasoning. The former is having a range of information while the latter is thinking logically and analytically. Intuition is something that usually occurs when an individual is confronted with new situation (Csikszentmihàlyi \& Sawyer, 1995); (2) Knowledge. This term can be defined as a combination of information, experience, context, interpretation, and reflection. Knowledge is rich information, action-oriented and leads to sensemaking and interpretation (Davenport, Delong, \& Beers, 1998).

Schemata and information processing. While information turning into embedded, organized, and interconnected knowledge structure, it leads to greater impact. However, individuals do not actively process all the information they confront, rather, they usually prefer to depend on a set of personal schemata to understand how to behave. That is why they can react to the different business situation with relatively little active information reasoning. Thus, it can help them to immediately do decision-making about business creation activities, considering the information they receive (Kiesler \& Sproull, 1982).

Cognitive scripts are defined as schematic knowledge structures in individual's mind, which determine one's self-diagnosis appropriate behavior in a specific situation (Gioia \& Poole, 1984). Information processing models are part of such abstract structures. The function of cognitive scripts is to simplify information process, but of course, individual's biases interfere with this process which affects judgment and decisions. The 
interference of biases through cognitive scripts can be both supportive or disincentive for business creation activities (Gioia \& Manz, 1985).

The following questionnaire was designed according to the above-mentioned factors:

(A) cognitive scripts:

(1) To what extent do you use algorithmic process (or use of formula) for decision making?

(2) To what extent do you use archives information for business activities?

(3) How much do you let your employee use their self-experiences of make decision in their own way?

(4) How much do you use of trial and error method for business activities decisions?

(5) What do you think of the effects of employees' behavior on your business activities?

(B) SME's development:

(1) Did the number of new customers grow your business within last three mounts?

(2) Did the unit of products sales grow for your business within last three mounts?

(3) Did the total sales of all product's categories increase within last three mounts?

These questions were designed into structured questionnaires and were filled by the 25 techno-entrepreneurs in a random sample.

\section{Regression Analysis}

To be confident about using regression analysis, the Durbin-Watson test was estimated. The result for this test is 0.68 which is reliable. Authors used enter method for regression analysis. The adjusted $R$ square is 0.825 which is very significant and indicates that $82 \%$ of the variability in the dependent variable is explained by the regression.

In coefficients table, all the constant and coefficients are significant. Beta coefficients for all independents variables (use of an algorithmic process, use of archived information, use of employees' experiences in their own way, use of trial and error method, and the benefit of a distinct employee) are 0.162, 0.195, 0.645, 0.236, and 0.449 . The regression equation for all dependent and independent variables is as follow:

$$
\left(\mathrm{Y}=-4.82+0.86 x_{1}+2.03 x_{2}+0.43 x_{3}+0.85 x_{4}+1.06 x_{5}\right)
$$

\section{Friedman Test}

Friedman's test is used to rank the independent variables. The rank of the variables with this test is as follow (Table 1):

Table 1

Friedman's Estimation Results

\begin{tabular}{lll}
\hline Variables & Mean & Rank \\
\hline Use of the algorithmic process & 3.96 & 5 \\
Use of archived information & 3.22 & 4 \\
Use of employees' experiences in their own way & 1.24 & 2 \\
Use of trial and error method & 1.1 & 1 \\
The benefit of the distinct employee & 2.4 & 3 \\
\hline
\end{tabular}

Source: authors.

It means that the significance of these variables on dependent one is as shown above. Figure 3 shows the software results for Friedman's test. Thus, the ultimate model of the study will be as follow: 


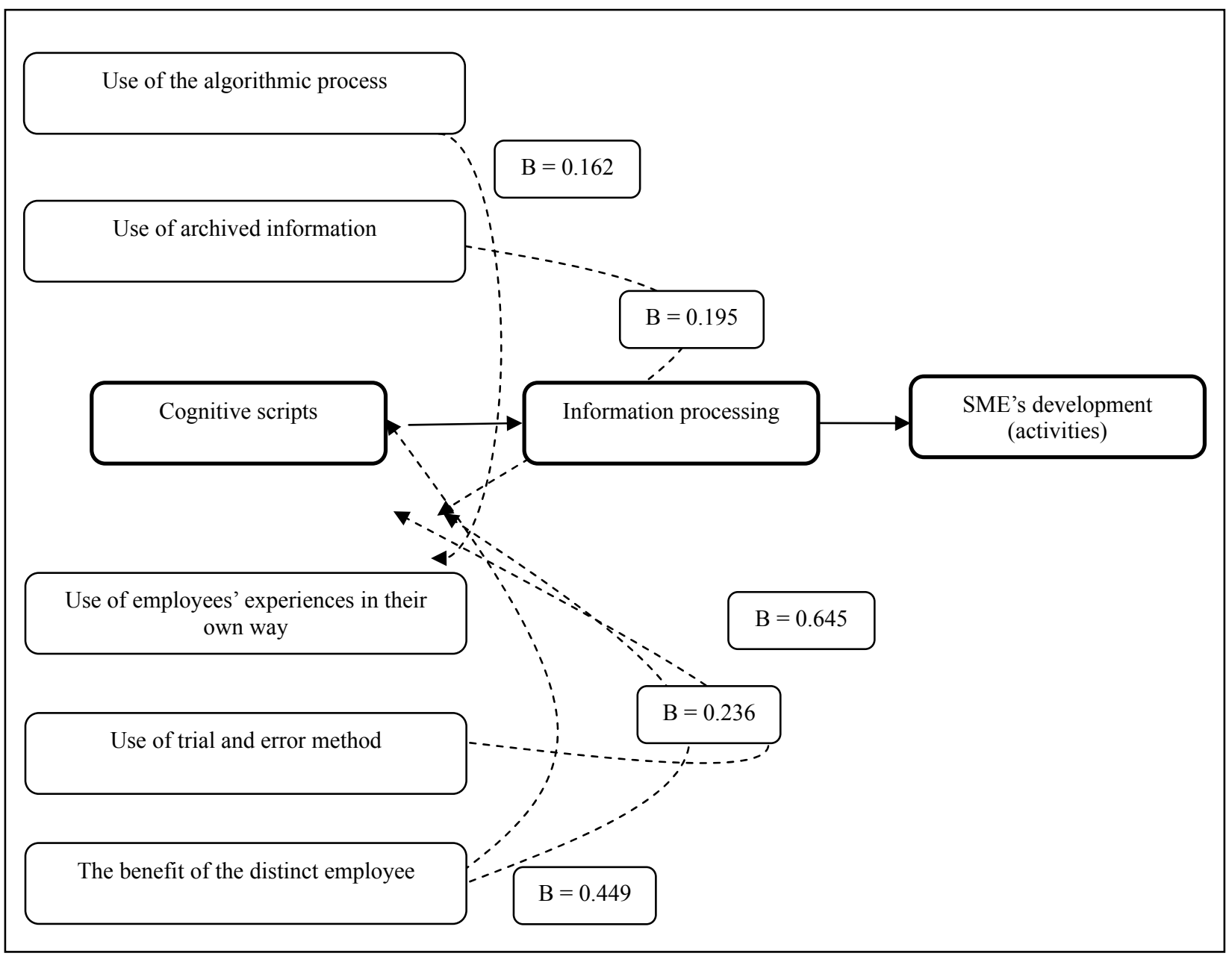

Figure 3. The ultimate model of the study. Source: authors.

\section{Conclusion and Discussion}

This study tried to identify the critical role of cognitive scripts in information processing and its effects on business developing activities, especially opportunity identification. Authors discussed that there is a little amount of knowledge about the role of individual as an information processor. Individuals grasp knowledge from environment and process it to identify a profitable business opportunity. Thus, it is obvious if there is noinformation processing, there will no any opportunity too. However, this process is not as simple as it looks. Scholars believe individuals' biases affect their knowledge processing through their cognitive scripts. This is the key functionality which has been discussed less than other topics.

In order to estimate the effect of information processing on business developing via cognitive scripts, authors designed a conceptual framework (Figure 2) and introduced some variables regarding literature. As regression analysis shown, because of the high amount for $\beta$ coefficient in three heuristic variables (use of employees' experiences in their own way, use of trial and error method, and the benefit of distinct employee), it can be concluded that entrepreneurs in the paper's sample benefit from heuristic information processing in their business development activities. Meanwhile, this result will prove the positive relation between dependent and independent variables in the study's assumption. Although this study tried to shed a light on the subject of 
cognitive scripts and its role in information processing and business development, there is still much more which should be studied in future researches.

\section{References}

Csikszentmihàlyi, M., \& Sawyer, K. (1995). Creative insight: The social dimension of a solitary moment. In R. J. Sternberg and J. E. Davidson (Eds.), The nature of insight (pp. 329-363). Cambridge Mass: MIT Press.

Davenport, T. H., Delong, D. W., \& Beers, M. C. (1998). Successful knowledge management projects. Sloan Management Review, $39(2), 43-57$.

Gartner, W. B. (1985). A conceptual framework for describing the phenomenon of new venture creation. Academy of Management Review, 10(4), 696-706.

Gioia, D. A., \& Manz, C. C. (1985). Linking cognition and behavior: A script processing interpretation of vicarious learning. Academy of Management Review, 10(3), 527-539.

Gioia, D. A., \& Poole, P. P. (1984). Scripts in organizational behavior. Academy of Management Review, 9(4), 449-459.

Hayek, F. (1937). Economics and knowledge. Economica, 4, 33-54.

Julien, P. A., \& Vaghely, I. (2002). From weak signals to strategy formation: A third piece of the puzzle. Frontiers of Entrepreneurship Research 2002.

Kiesler, S., \& Sproull, L. (1982). Managerial response to changing environments: Perspectives on problem sensing from social cognition. Administrative Science Quarterly, 27, 548-570.

Timmons, J. A., \& Spinelli, S. (2004). New venture creation. Boston: McGraw-Hill/Irwin.

Vaghely, I. P., \& Julien, P. A. (2010). Are opportunities recognized or constructed?: An information perspective on entrepreneurial opportunity identification. Journal of Business Venturing, 25(1), 73-86. 